\title{
IDEOLOGÍA, TECNOCRACIA Y LIBERALISMO
}

\section{Fernando de Lucas y Murillo de la Cueva*}

Después del triunfo del Partido Popular en las legislativas de marzo del 2000, $\mathrm{y}$ con la reconfiguración del arco parlamentario, parece pertinente replantear el rumbo que viene tomando la política en nuestro país (y, en definitiva, Europa). Para ello, el autor se cuestiona (en un debate ya existente desde hace bastante tiempo, pero no por ello menos actual sobre el problema de democracias parlamentarias. Así, pues, nos preguntamos - desde una perspectiva que pretende incentivar discusión política, qué ocurre con la misma política a través del papel relevante de la ideología, la tecnocracia y el liberalismo. Lo que supone polemizar sobre el discurso economicista el problema del liderazgo político y la crisis de las Instituciones modernas.

"La circulación de ideas, de preferencias, de programas diversos en un régimen democrático sólo puede resultar beneficiosa para la propia democracia. La oposición, no sólo la político-parlamentaria, sino la verdaderamente social e intelectual, desarrolla su cometido cuando elabora ideas, expresa preferencias, produce programas, apunta soluciones que desafían a los gobiernos de turno y estimulan a la opinión pública. También cumple su cometido cuando ejerce el control sobre los gobiernos y aplica su crítica a las decisiones y a las indecisiones de los gobernantes. Incluso cuando cuestiona los modos de gobierno y el eventual alejamiento de los valores codificados, no sólo en la Constitución sino también en los principios éticos". Pasquino, Gianfranco: La democracia exigente (trad. Pilar González Rodríguez). Alianza, Madrid, 2000.

* Profesor de la Universidad Complutense y miembro de la Asociación CastellanoManchega de Sociología. 
En marzo del 2000, Cruz Roja, Naciones Unidas y los medios de comunicación en general, nos mostraron con cifras algo que ya sabíamos desde hacía tiempo: el envejecimiento acelerado de los países europeos y, sobre todo, el de España, que acabará convirtiéndose para el 2050 en la nación más "vieja" del mundo (con una media de edad de 54,3 años).

Por otro lado, en los últimos comicios generales (12 de marzo del 2000), el Partido Popular no sólo obtuvo la victoria (lo que ya se esperaba), sino la mayoría absoluta (lo que fue una sorpresa).

Ambas noticias no tienen una relación directa, pero la pregunta que nos hacemos es si una supuesta política de la eficacia (supuestamente aideológica y, en este caso, absolutamente mayoritaria) será capaz de solventar problemas graves (problemas estructurales) como son, por ejemplo, los derivados de la relación de tres variables importantísimas: envejecimiento poblacional + sistemas de pensiones y de protección social + políticas de inmigración. Creo que no y lo hago desde la idea de que es necesario reivindicar una política declarada ante las nuevas viejas políticas (llámeselas "postpolíticas" si se quiere) que, aprovechando coyunturas económicas, tienden a eliminar la deliberación y, consecuentemente, periclitan la ciudadanía.

Por lo tanto, vamos a revisar el problema del debilitamiento de la política, como puede verse a través de sus actores y sus procesos (tanto el líder como el liderazgo políticos ), y vamos a reivindicar la única manera que creemos posible de convivir y solucionar los problemas: a través de la política. Una política declarada donde puedan participar (y no tiene por qué ser demagógicamente) instituciones, actores sociales, ciudadanía. Una política democrática, dialógica y abierta a sus protagonistas. Esta es, para nosotros, la única política responsable, y no las otras políticas, autocalificadas de la misma manera pero que esconden sus intereses ideológicos, quizás por ignorancia, quizás por vergüenza.

En una democracia representativa como la nuestra, la sustitución del discurso ideológico (que no tiene por qué ser irresponsable) por el de la eficacia, convierte a la política en una management science. Este, a fin de cuentas, es el discurso del liberalismo, que emplea la economía y la técnica de gobierno para asegurar su triunfo. Así se difuminan tanto el liderazgo político, la política y la Democracia. El "fin de la historia" es una empresa, pero recordemos, una empresa con ideología, aunque esta se halle enmascarada.

En las siguientes páginas me propongo abordar estos asuntos:

Intentaremos explicar cuál es el significado de la palabra "técnica" para distinguirlo de la "tecnología". Una vez visto esto podremos apreciar más convenientemente qué significa "tecnocracia", incluyendo otras apreciaciones como las que se refieren al término "tecnarquía" y "burocracia" (que difiere de los dos conceptos anteriores). A partir de esta introducción podremos comprender como bajo esos supuestos late un pensamiento pretendidamente "aideológico" pero que, realmente, es conservador. 
Comprenderemos que el neoliberalismo es una ideología neoconservadora que, como decimos, se enmascara. También hablaremos de la politización de los técnicos así como de la tecnificación de la política. Tales problemas, provenientes de la crisis de la modernidad, abren una segunda parte -claramente crítica-, sobre el papel de la economía, el liberalismo, la ideología, la tecnocracia y, por fin, la Democracia. Así, pues, comencemos sin más dilación.

Nadie puede negar que la técnica es uno de los rasgos que caracterizan nuestro tiempo. Bien es cierto que, en su acepción histórica, parte de una conceptualización peyorativa. No así en los enciclopedistas y fisiócratas que encontraban en la técnica y en el empleo racional de las ciencias las herramientas para arribar a una sociedad futura feliz. En este caso, como también en el socialismo utópico de Saint-Simon, la técnica no negaba el humanismo (como hoy se duda), sino que lo apuntalaba gracias a la intervención de un cuerpo de sabios (dotados de poder espiritual) que coadyuvarían al advenimiento de una civilización del trabajo sin clases. El marxismo, como se sabe, se calificó por Marx y Engels, como científico.

Así, pues, definamos lo que entendemos por técnica:

"Conjunto de conocimientos prácticos, instrumentales y de habilidades que capacitan al hombre para mejorar su bienestar: sea utilizando las fuerzas naturales, sea aprovechando las ventajas que se desprenden de su vida en sociedad" ${ }^{2}$.

Definición de la que no trasciende juicio peyorativo alguno. Así, pues, podemos decir que la técnica no es en sí perjudicial. Es más, caracteriza al hombre. Si el homo faber aparece, es porque maneja instrumentos. La posibilidad de oponer el pulgar al resto de los dedos de la mano, nos capacita para asir con fuerza y manejar instrumentos, es decir, ampliar las limitaciones de nuestro propio cuerpo. Sin la técnica el hombre no habría salido de las cavernas.

Tanto la antropología física, como la antropología filosófica, la económica y la cultural (por no volver a citar todas las diversas formas de estudios antropológicos), reparan en estos asuntos ${ }^{3}$, por lo que no podemos hablar de cultura (en el sentido antropológico del término), sin hablar de la técnica. Así, Max Scheler , y el mismo Ortega ${ }^{5}$, comprenden a la técnica como una actividad que realiza el hombre -carencialreformando la naturaleza y adaptándola a su provecho. Zubiri ${ }^{6}$, por su parte, afirma que la técnica ocupa el camino entre el saber y el intervenir. En definitiva, la técnica es una especie de mundo intermedio, así como la herramienta es un mediador entre el hombre y su entorno vital. El problema surge cuando aquélla madura y llega a constituir esa realidad intermedia: realidad de segundo grado o infraestructura cultural. Más aún, en su madurez máxima, se vuelve autónoma y tiende a romper las finalidades que le imponía la razón especulativa, hasta el punto que se constituye en fundamento de sí misma, se deslinda del saber científico y campa sóla "como un juego" ". La técnica, así vista, es otro ejemplo de cómo el hombre, creador, se estanca en las cosas que objetiva, imagina, descubre e inventa. Salvo que esta objetivación de la técnica puede convertirse en un sucedáneo del instinto del hombre y, por lo tanto, enajenarlo. 
La técnica, comprendida también como una metodización del trato con las cosas, no es lo mismo que la tecnología. A pesar de la fuerte sinonimia que ambas palabras poseen y que las hace intercambiables, entendemos a la tecnología como:

"Cuerpo de conocimientos disponibles para el moldeamiento y elaboración de instrumentos y artefactos de todo tipo, para la extracción o colección de materiales de todo tipo"

Si la técnica es conocida y utilizada por el hombre desde que es hombre, ella, junto con la tecnología, han transformado nuestro mundo de forma más que relevante y a ritmos no conocidos hasta la fecha:

"La humanidad ha venido midiendo su progreso históricamente en términos de tecnología, con el resultado de que cada era nos ha sobrepasado más rápidamente que las anteriores. La Edad de Piedra duró millones de años, pero la siguiente, la del Metal, sólo cinco mil años. La Revolución Industrial (de primeros del siglo XVIII a últimos del siglo XIX), doscientos años. La Era Eléctrica (de comienzos de siglo a la II Guerra Mundial), cuarenta años. La Era Electrónica duró veinticinco años y la Era de la Información ya tiene veinte, evolucionando rápidamente desde lo que podríamos llamar Infolítico Inferior al Infolítico Superior o Información hipermedia. Comparemos la velocidad de este proceso con el pasado: El homo sapiens aparece hace 1.400 generaciones, pero sólo desde hace 200 comenzó a utilizar la escritura; la imprenta es de antes de ayer, la venimos utilizando las últimas veinte generaciones"”.

Pero la tecnología no se concentra sólo en invenciones, máquinas e ingenios, sino que entronca con el desarrollo económico, convirtiéndose en una de las principales fuentes del poder público de las sociedades modernas ${ }^{10}$. Esto lleva a Galbraith a decir que lo que determina la forma de la sociedad económica es el conjunto de los imperativos de la tecnología y de la organización, pero no de las imágenes ideológicas. Queda el camino abierto, de esta manera, a la tecnoestructura ${ }^{11}$ (BIS).

En este orden de cosas, la tecnología instaura un determinismo técnico de trayectoria lineal (desde las soluciones más simples a las más complejas) que somete a las instituciones sociales a su orden, convirtiéndose en una nueva cultura inamovible, prótesis generalizada, que nos libera de la coerción de la naturaleza agresiva, pero instaura una nueva coerción aún más fuerte. Los momentos de decisión, en el ámbito político, no se sujetan por la competencia jurídica (protectora de los derechos), sino por la competencia técnica.

La traslación de la verdad científica y/o técnica al ámbito de la política, se convierte en tecnocracia: gobierno de sabios, científicos, técnicos, expertos y gestores. Y la mejor política es sólo una, la política del one best way. Los antagonismos ideológicos quedan desactivados, así como toda apelación desaparece, pues, ante la autoridad de la ciencia, no cabe discusión alguna ${ }^{12}$.

Saint-Simon podía creer en un gobierno tecnocrático de la sociedad y poseía una visión elitista, pero no podría ser puesto en el mismo lugar que 
Taylor y Ford, que trascendieron la esfera empresarial. Veblen, por su lado, creía en la Alianza Técnica como un nuevo sistema y forma de gobierno. Si bien, el pensamiento tecnocrático puede encontrarse en áreas de la izquierda (como en Lenin y Stalin), remite a una ideología que llamaremos neoconservadora, en la que la política es algo infectado y los políticos son quienes transmiten el virus.

Burnham en La revolución de los directores ${ }^{13}$ hablaba de cómo una nueva casta emergente de técnicos comenzaba a desplazar a la burguesía en el capitalismo gracias a su habilidad, no en las técnicas productivas, sino en las de la organización. A medida que los burgueses encontrasen imprescindible su concurso, acabarían los técnicos por tomar el poder. En fin, el tecnócrata continúa y cierra el proceso que encuentra al hombre renacentista como padre del burgués, de la misma manera que el tecnócrata es hijo del anterior. Al final, el mayordomo de palacio triunfa sobre el rey holgazán.

Desde una reacción elitista, Ortega nos advierte que estos técnicos no pueden tomar el poder, pues en su esencia no está mantener una cultura. Después de haber accedido a ella súbitamente con el resto de la masa, no la conoce, no la comprende. Si en el marxismo se considera a los tecnócratas como servidores del capital, no es menos cierto que en el pensamiento liberal se criticó (lo que en la actualidad hay que revisar) a los tecnócratas por ser unos irresponsables de ideas alejadas de la realidad.

En el paso final se llega a la tecnolatría, estadio máximo de glorificación del tecnócrata. Pero no parece que ese día arribe en algún momento, aunque es posible que la tecnocracia encuentre un buen caldo de cultivo en la postmodernidad, pues los hombres que la componen presentan supuestas soluciones a los diversos y específicos problemas de la nueva macrorrealidad.

García Pelayo define a la tecnocracia de la siguiente manera:

“...estructura de poder en la cual los técnicos condicionan o determinan la toma de decisiones, tendiendo así a sustituir al político (o sustituyéndolo definitivamente) en la fijación de las policies y a los burócratas tradicionales en la operacionalización de las decisiones o en su participación en la decisión misma" ".

Lo que nos aclara que tecnocracia no es lo mismo que tecnoestructura, aunque algunos autores la confundan ${ }^{15}$, ni tampoco el tecnócrata (que es el agente de la tecnocracia) es exactamente igual al técnico:

“...los tecnócratas -si tienen una cultura técnica que les permita dirigir un Estado o una empresa moderna, no son técnicos. Asumen una función de dirección y coordinación en las sociedades industriales sin tener práctica de ninguna técnica en particular. Esto es lo que diferencia al tecnócrata de la masa de técnicos que tiene bajo sus órdenes: no representa la técnica en el poder, pero asegura la elección de una política (gubernamental o industrial) a partir de los datos técnicos" $"$. 
Capanna $^{17}$, por su parte, introduce el concepto tecnarquía, como una orientación del ser en la que predomina la acción sobre todo pensamiento contemplativo, pero en una acción orientada a la conservación y pervivencia del orden inherente a la naturaleza. En este sistema social ${ }^{18}$ hay cambios, pero no evolución.

El tecnarca es el agente de la tecnarquía, y este hombre se caracteriza por su eficiencia (posee el dinamismo y la actividad del ejecutivo que hace, no piensa); disponibilidad (sirve a cualquier tipo de objetivos mientras se le deje desplegar su eficiencia); e imagen (estable y útil como resultado de su eficiencia) ${ }^{19}$.

Pero lo que identifica a ambos (tecnócrata y tecnarca) es que tienden a sustituir o debilitar al homo politicus ya que aparecen en los ámbitos de decisión de los ejecutivos como políticos de la eficacia o como tecnoestructura que no decide, pero orienta con sus recursos técnicos. El homo politicus y el tecnócrata, o ".tecnarca", acaban por encontrarse en el poder, ya que el primero se orienta hacia el ejercicio y conservación del poder y el segundo funda su poder en la técnica que es consustancial a toda acción de gobierno, al menos en las presentes democracias. Los problemas de gobierno de las naciones, de las fuerzas políticas y partidos de masas, necesitan, invariablemente, de especialistas en las técnicas de organización

Mas estos especialistas y técnicos pueden ser perfectamente burócratas, con lo que toda esta disquisición se vendría abajo. Conviene, de todas formas, que distingamos más precisamente lo concerniente a la burocracia y la tecnocracia.

García-Pelayo $^{20}$ diferencia entre buroestructura y tecnoestructura y encuentra que la primera está sujeta por una serie de reglas de carácter primordialmente jurídico, mientras que las de la tecnoestructura son de tipo técnico. Así, pues, los burócratas están sujetos a una organización y a un funcionamiento de la misma constreñidas por una imperatividad formal, pero las de la tecnoestructura son flexibles, posibilitando su adaptación a los cambios tecnológicos y a los nuevos problemas. Su legalidad remite a lo fáctico, a la necesidad de las cosas, no a lo jurídico y, por ello, estos técnicos son los únicos competentes.

Por otro lado, la jerarquía de autoridad de la buroestructura es monocéntrica, vertical, en cambio en la tecnoestructura es pluricéntrica, horizontal, y la autoridad que se posee es en un campo determinado, el de los problemas que tiene que resolver. Por último, la buroestructura se constituye por funcionarios que ingresan al servicio a través de concurso ${ }^{21}$, cobran un sueldo prefijado y ascienden por méritos y antigüedad. En cambio, los miembros de la tecnoestructura son contratados e, incluso, pueden efectuar sus servicios dentro del Estado, el Ejecutivo y las fuerzas políticas, a la vez que en la empresa privada.

En definitiva, los tecnócratas y/o tecnarcas, acceden al campo político sin estar limitados a las reglas del estamento burocrático, sin estar constreñidos por el campo de lo jurídico, aunque sus errores, en vez de ser castigados con una sanción administrativa, suponen su fracaso, pero sus éxitos cotizan a la alza. 
El papel de estos especialistas en los Estados postmodernos los convierte en tecnócratas o, como cree Toffler ${ }^{22}$, en "ad-hocracia". Es decir, las necesidades técnicas de las grandes estructuras de gobierno permiten la afluencia de una serie de expertos o equipos ad hoc que son construidos o llamados para solventar los problemas de corto o limitado plazo. Esto provoca que los problemas, resueltos bajo la competencia jurídica (que garantiza, querámoslo o no, el Derecho), se solucionen técnicamente por una serie de personas que no se orientan más que por la eficacia, su eficacia.

Un exceso de positivismo puede eliminar el espíritu de la ley, puede deshumanizarla, pero un exceso de tecnocracia (o ad-hocracia) transforma el Derecho en una management science, con lo que esto comporta: esto es, la emergencia de una nueva legitimidad que convierte todo lo demás en subsidiario de ella:

"Tal principio de legitimidad podría formularse así: es legítimo lo que es eficaz, y es eficaz lo que promueve y asegura el desarrollo tecnoeconómico en unas condiciones ambientales y en una coyuntura dadas, ya que ello es, en última instancia, condición para la vigencia de cualesquiera otros valores. Dicho principio tiende a ser, así, en el mundo actual una variable independiente frente a la cual todos los demás criterios de legitimidad serán variables dependientes, contingencias o ritualismos. A esta nueva especie de legitimidad (y, con ello, de autoridad) funcional, quizá no rigurosamente formulada, pero no por eso menos sentida, podemos considerarla como la típica legitimidad de la época tecnológica, una legitimidad de especie racional, sin duda, y más concretamente de especie racional-funcional, pero en cuyo nombre se pueden justificar fenómenos parciales o globales ilegítimos desde otros principios de legitimidad"

Desde esta nueva legitimidad ("aideológica" pero que, en realidad, es una especie de neoliberalismo camuflado), perspectiva que gusta emplear el razonamiento técnico, se lamenta la complacencia de los políticos con respecto a los desheredados del progreso económico y, así, es posible justificar todo: "sociedades de dos tercios"," "males necesarios", etc., que excusan cualquier coste (social, fundamentalmente) por una acción de gobierno liberada a la técnica y a la búsqueda de soluciones por un sólo camino. Sin anticipar demasiadas reflexiones que pretendo exponer al finalizar este capítulo, podemos convenir que, en este orden de cosas, la acción política y, el liderazgo político en concreto, deben presentar resultados, en política laboral y económica principalmente. En esa persecución de resultados, se puede pedir el sacrificio de los ciudadanos o se puede intentar convencer a los mismos, a través de los media, del buen rumbo de la economía y del empleo en el país. De este modo cabe recortar las prestaciones sociales, flexibilizar el empleo, descargar a las empresas de parte del lastre de la Seguridad Social y someter, aún más, la política social a la económica, pues la razón técnica nos dice que, creando riqueza, alcanzando ciertos niveles en el PIB, todo lo demás vendrá dado después 
En el trasfondo de la tecnocracia late el pensamiento neoliberal, neoconservador, que socava los mismos valores que sustentaban al liberalismo y al ethos burgués: cuando un burgués presenciaba la apertura de una represa, contemplaba un hito más en el avance del progreso, pero el tecnócrata, el tecnarca, no ve en ello nada más que la conclusión de parte de un plan de obras preestablecido, o una modernización de estructuras obsoletas ${ }^{26}$. La tecnocracia pierde el horizonte.

García-Pelayo encuentra en la tecnocracia el caldo de cultivo del que surge un tipo oportunista de político o "político pragmático" también llamado político manipulador":

"...que encarna, de un lado, la crisis de la personalidad moderna y, de otro, profundiza y enrarece la crisis de la política y que, en resumen representa una percepción tosca, empírica y elemental de las cosas"

El tecnócrata (sea o no un futuro, o presente, "político manipulador") desileologiza o enmascara la ideología tras la técnica y la ciencia. Desocializa y despolitiza hasta el punto que, su concurso y presencia aumentadas, provoca la declinación del político clásico y, por lo tanto, de los Parlamentos. El tecnócrata tiende a amplificar, artificialmente y a través de esa nueva legitimidad que le acompaña, el poder del ejecutivo:

"El Parlamento es una institución nacida en la era pre-industrial, desarrollada plenamente en la era industrial y declinante (si no lo remedian las adecuadas reformas) en la época post-industrial o tecnológica... Digamos solamente que la colaboración de los tecnócratas públicos y privados, unida al hecho de que las actividades económicas y tecnológicas caigan por razones funcionales en la esfera del Gobierno y, por tanto, que los grupos de intereses presionen preponderantemente sobre éste, así como que importantes decisiones se tomen en el seno de pequeños grupos de expertos 'que pueden proseguir sus estrategias a largo plazo, mientras que los Parlamentos tienen una duración relativamente breve' , todo ello conduce a una disminución del poder y de la significación del Parlamento dentro del sistema" ${ }^{, 28}$.

García-Pelayo $^{29}$, después de observar que con la disminución de los poderes del Parlamento crecen los del Ejecutivo igualmente, afirma que la ampliación de funciones y poderes del Ejecutivo ha ido acompañada, a su vez, de fenómenos de especialización, división y subdivisión de las atribuciones asignadas a distintas instancias, autoridades, organismos, agencias, institutos, etc., que, si bien están sujetos a un ministerio, Consejo de Ministros o a la Jefatura del Estado, en la práctica gozan de una amplia esfera de acción autónoma.

De nuevo, la tradicional separación de poderes, se debilita al conectar los expertos del Estado y del Ejecutivo entre ellos y las empresas (incluidas la Banca y los medios de comunicación). Así, la política muestra una doble faz: la abierta, publicitada, y la cerrada, en comités y agencias.

Pero debemos aquilatar cuestiones. Según lo visto, podríamos decir que la política ha muerto definitivamente y que las ideologías, como dice Fernández de la 
Mora $^{30}$ en su libro, El crepúsculo de las ideologías, desaparecen. Aún así, no somos profetas en el desierto. Las fuerzas que actúan sobre la política pueden debilitarla, pero no hasta el punto de eliminarla. Más aún cuando el papel de los tecnócratas no es omnipotente ni omnipresente, aunque, bien es cierto, que su relevancia, su presencia y el pensamiento que se desprende de ellos, es mayor en nuestros días.

Touraine advierte que la racionalidad instrumental no es el principio integrador de la modernidad:

"Lo cual muestra el error de todos los que, sobre todo tras la Escuela de Francfurt, tanto con ella como contra ella, han acusado a la sociedad de no tener otro principio de legitimación que la técnica, por tanto, de ser tecnocrática. Idea extraña, a decir verdad, cuando se la aplica al siglo que ha visto a Hitler y a Stalin, a Mao y a Fidel Castro, a Roosevelt y a De Gaulle, por no mencionar sino a dirigentes políticos importantes que han definido claramente la naturaleza que daban a su legitimidad"

Touraine explica que nunca los medios se han convertido en fines, que ninguna sociedad es sólo una máquina, sólo una burocracia. En realidad, el problema, para Touraine, estriba en que:

“... la debilidad de nuestras sociedades no deriva de la desaparición de los fines destruidos por la lógica interna de los medios técnicos sino, por el contrario, de la descomposición del modelo racionalista, roto por la modernidad misma, $\mathrm{y}$, por tanto, por el desarrollo separado de lógicas de acción que ya no se refieren a la racionalidad: búsqueda del placer, del estatuto social, del beneficio o de la potencia" ${ }^{32}$.

No me parece que mi análisis contraste con el de Touraine. Es cierto que ningún país es sólo tecnocracia y/o burocracia. En todo caso, los sistemas de gobierno, antes de ser tecnocráticos puros, podrán ser decisionistas o pragmáticos.

Touraine tiene razón cuando afirma sobre la importancia de la racionalidad práctica y la utilidad de la técnica. Por ejemplo: sin instituciones, es difícil garantizar el proceso de orientación política. Este, a su vez, asegura el necesario pluralismo para que se pueda hablar de una sociedad democrática. Cuando las instituciones funcional mal, o no son suficientes, es necesaria su institucionalización o perfeccionamiento.

"Entonces resulta que es menester la institucionalización política, es necesario crear otras instituciones, o perfeccionarlas, o sustituir, las antiguas por otras nuevas. Toda revolución, todo movimiento político, pretende consolidarse a través de instituciones correspondientes, tanto del Estado-sujeto como Estadocomunidad."

Pues bien, todo proceso de institucionalización política, necesita cierta tecnificación. Y este proceso se opera, habitualmente, mediante la racionalización del poder político y de los elementos a su servicio, tanto en el plano normativo y jurídico como en el económico y social (planificación)34. Un ejemplo de necesaria tecnificación, de racionalización, lo encontramos en la Constitución de la República 
de Weimar y en la Constitución Española de 1978. Especialistas renombrados participaron en su elaboración. Compartimos la necesidad de la técnica como dice Touraine. Pero el autor galo hace referencia, más que a la técnica a la racionalidad. Así, pues, esta se desvirtúa cuando la planificación se traslada al campo normativo y jurídico.

Aún así, los mismos tecnócratas se politizan al participar en política, lejos de ser un estamento unificado o una especie de lobby y, según la estructura de la que formen parte, pueden convertirse en grupos de interés que pelean contra otros grupos semejantes pertenecientes a otras organizaciones rivales. Así prolongan la dicotomía schmittiana amigo-enemigo como substancia de lo político.

En su pugna por hacer prevalecer sus opiniones, por recabar más poder, en el uso de su posición dentro de Ejecutivo, empresa y fuerzas políticas, se politizan. Incluso, en el otro lado, y como forma de presentar una buena imagen de gobierno, el político clásico puede disfrazar sus intereses y liderazgo con expresiones, decisiones y gestos técnicos. Y aquí es donde se halla otro de los motivos del debilitamiento de la política y del carisma: los líderes políticos se ven forzados a utilizar expresiones técnicas como garantía de una política eficaz, mientras que los técnicos, sin una tradición de cultura política, se politizan.

Así, pues, en una dinámica (parafraseando a Touraine) en la que el problema es la ruptura de la racionalidad, creo que la tecnificación de la política enmascara una ideología tras una supuesta racionalidad, lo que no parece extremadamente positivo para la razón misma, además de deslegitimar el empleo de la técnica.

Lucas Verdú, en la década de los sesenta, hablaba ya de "Ciencia Política para conservadores" ${ }^{, 35}$. El profesor emérito desemascaraba el intento de búsqueda de legitimación a través de la instrumentalización que de la Ciencia Política hacía el neoconservadurismo.

Así, la cientificidad de los presupuestos técnico-políticos del neocoservadurismo, invalidaría los movimientos de izquierda y, por extensión, cualquier ideología: fascismo, democracia cristiana, anarquismo, socialismo y comunismo. Un reproche común de los técnicos al sistema político se encuentra en que éste emplea, para su funcionamiento cotidiano, conceptos trasnochados:

"...como la lucha de clases, y el culto a las ideologías que ya han caducado: liberalismo, marxismo, nacionalismo... Frente a las transformaciones en curso en el orden técnico, la experiencia acumulada por las generaciones no aporta otra cosa que criterios engañosos, como ocurre con la distribución de los hombres entre la derecha y la izquierda y también con la oposición entre el mercado y el plan. Son, pues, indispensables unas modificaciones radicales para acabar con las consignas y prejuicios de antaño. ${ }^{36,}$

La sustitución de la ideocracia por la tecnocracia surge del archiconocido desgaste de las ideologías, empleando la ciencia para esgrimirla contra el resto de sus adversarios. En el camino hacia la institucionalización de la tecnarquía, será necesario desembarazarse de lastres: 
"Todas las ideologías se hallan caducadas, tan caducadas como las estructuras político-económicas de las que son contemporáneas. Han sido establecidas antes de la segunda fase de la revolución industrial, la que inaugura la posibilidad de la abundancia a escala mundial'. Conviene observar los fenómenos económicos y sociales de nuestra época evitando referirse a los textos de los pensadores 'respetables, pero superados'. El problema estriba en que el hombre encuentre 'el estado del espíritu indispensable par poner en acción el equipo de*2' y no podría lograrlo sino abandonando los principios que, hasta ahora, han inspirado las elecciones políticas" ${ }^{37}$.

Cierto es que el marxismo empleaba la ciencia, o más correctamente, se identificaba con ella. Pero el neconservadurismo, el neoliberalismo también, la utilizan, la instrumentalizan. Es por esta razón por la que Lucas Verdú titula su artículo Ciencia Política para y no de neoconservadores ${ }^{38}$ y por la que, a su vez, dice que a esta ciencia política le faltan las mayúsculas pues está huérfana de la generalidad, objetividad e imparcialidad necesaria para toda empresa científica.

Uno de los problemas de esta instrumentalización se encuentra en que el neopositivismo neoconservador no posee la fe que el positivismo clásico tenía en el progreso, en ese gran relato que abría el camino a la felicidad humana. La decadencia de este relato se halla en que se ha vaciado de contenido moral (que puede ser discutible, en efecto, pero lo tiene) pues su única premisa es alcanzar el poder. Para ello, no apoya sus puntos de vista en la tradición, la Historia o el Derecho natural (otros relatos desgastados), sino que, a juicio de Lucas Verdú, prefiere recurrir a las leyes de la Ciencia Política que demuestren la verdad inconmovible de sus concepciones políticosociales. Pero esta burda instrumentalización falsea y contamina a la misma Ciencia Política:

"Quiero decir que al reinterpretar los neoconservadores ciertos postulados cientificopolíticos elegidos (a saber, el desgaste de las ideologías, la despolitización, la ley de bronce de las oligarquías y la personalización del poder) e insertarlos dentro de la 'no-ideología' neoconservadora, se adultera el sentido de esas tendencias comprobadas por los politicólogos... El neoconservatismo señala con delectación cómo el poder se personaliza aun dentro de las democracias y cómo los partidos de masas son, en el fondo, dirigidos por un grupo restringido de personas. Pero esto no es negado por los otros movimientos políticos ni pueden extraerse consecuencias desmesuradas en favor del aristocratismo, 'elitismo' y personalismo caros al neoconservatismo. Las ideologías socialista, democristiana y otras no van a dejar de serlo porque en el seno de sus movimientos se compruebe el prestigio inusitado de alguno de sus líderes y el mando efectivo de unos escogidos" ${ }^{39}$.

A fin de cuentas, el neconservadurismo, latente o manifiesto en los mismos neoliberales, es una ideología; ideología cuya táctica es esconderse tras el manto de la ciencia (como así hizo el darwinismo social).

Minkengerg e Inglehart, tratando el neoconservadurismo en Estados Unidos, opinan que surge como respuesta (o reacción) al emerger del postmaterialismo y de 
la nueva agenda de la izquierda. Este neoconservadurismo, entre otras cosas, desea el regreso de las reaganomics ${ }^{40}$ y el progreso tecnológico. Pero es Bryan Turner quien presenta un caso más claro de supuesta desideologización en la aparición del thatcherismo. De forma que las divisiones tradicionales entre política conservadora, liberal o socialista, fueron desmanteladas por la aparición de este tipo de neoconservadurismo personalizado en la figura de la "Dama de hierro". La economía del laissez-faire que late bajo esto, no se constreñía a Gran Bretaña:

"Mientras diversos gobiernos y sociedades industriales parecen mostrar ideologías diferentes, encontramos también una convergencia clara en la forma de quedar dominadas estas políticas a las prácticas neoconservadoras de mercado. ${ }^{41}$,

Este neoconservadurismo, conecta, según lo visto, y entronca con la tecnocracia (si es que, en ocasiones, no son la misma cosa). Y no sólo trasciende fronteras, sino que, dentro de las naciones, se filtra en todo el arco político:

"Conviene señalar que el neoconservatismo no se integra en un solo partido político, sino más bien se presenta en varios grupos e incluso fácilmente se encuentran políticos con cierta mentalidad neoconservadora dentro de movimientos políticos liberales, democristianos y socialdemócratas" $"$.

Así, pues, las tesis de Touraine, repito, no las encuentro erróneas, pero no es menos cierto que la manipulación de la técnica en lo político deshace la racionalidad que el maestro galo defiende.

Los dilemas de la tecnificación de la política no acaban aquí. Habermas ${ }^{43}$ opina sobre la ideología que yace en el intento de hacer prevalecer la racionalidad tecnológica. Advierte sobre cómo se legitima a través de su introducción en el proceso de la investigación científica y su aplicación técnica, eliminando toda deliberación.

Marcuse $^{44}$, por su parte, no duda en que la concentración del poder económico, sumado al político y a la tecnología como instrumento de dominación, bloquee todo tipo de disensión. De esta manera, ciencia, economía, tecnología y política quedan modificadas, siendo, en ocasiones la política el último motivo.

Por ejemplo, en el ámbito del liderazgo político, estos usos de la política (como expresión de la verdad científica), tienden a eliminar, como dice Habermas, la deliberación, que es uno de los pilares de la democracia. Estas fuerzas, como antes hemos dicho, son proclives a crear una cultura sin dialogía, en la que se informa, pero no se comunica, lo que puede convertir al proceso del liderazgo en propaganda, que es una técnica de información persuasiva.

Los problemas de dirección de las democracias desarrolladas parecen clamar por la aplicación de las técnicas de gobierno, organización y decisión. En los esfuerzos del Gobierno español por obtener de la Unión Europea, dominada por los eurócratas ${ }^{45}$, ayudas para resolver los graves problemas de la agricultura (aceite de oliva, Fondos de Cohesión, etc.) frente a la política mantenida por Alemania y otros países, asistimos a una lucha por intereses económicos más que por ideologías. 
Así se puede llegar al modelo de político debilitado de la postmodernidad. Uno de sus mejores representantes lo encontramos en el anterior primer ministro británico, John Major, político gris, que contrastaba con el liderazgo de hierro de su predecesora.

Jones y Hudson ${ }^{46}$, en su estudio sobre la cualidad del liderazgo político en John Major, afirman que su atributo político más importante se hallaba en la creencia del electorado en que podía gobernar el país como una empresa. En su estudio de caso, ambos autores llegan a la certeza de que las características más importantes del líder remiten a su efectividad:

“...las características que hemos encontrado como más importantes, se refieren con mayor cercanía a la habilidad del primer ministro para hacer su trabajo (más aún que los atributos de su propia personalidad). Este es el caso particular de la efectividad, por ejemplo, que ha sido uno de las más importantes características del primer ministro. Esto nos ofrece una información preclara del primer ministro y, por lo tanto, de su competencia y habilidad para negociar con políticas futuras. Y muestra también que, cuando un primer ministro es del gusto o no de los ciudadanos, no es tan relevante como cuando un primer ministro es visto como "efectivo'",

Major debió parecer eficaz durante cierto tiempo a los británicos, pero nunca un brillante político. Su imagen fue la de un gestor gris atenazado por el pasado thatcheriano que creyeron necesitar los isleños.

Mas una forma de ver así la tecnocracia, ligada al neoconservadurismo, puede inducir a una visión maniquea, como si hablásemos de "defensores de la libertad" (políticos clásicos) versus "oportunistas peligrosos" (tecnócratas). Podemos «desdemonizar» a los tecnócratas y colocarlos en otra postura:

Cabe la posibilidad de que los técnicos, y los tecnócratas, recaben mayor relevancia no por su asalto al poder político, ni por la necesidad de ellos en el entramado de toda organización compleja, ni porque suplanten y debiliten al líder político, sino porque los tecnócratas surgen tras la decadencia del líder y el liderazgo político. Son, desde esta afirmación, consecuencia y no causa.

Una de las razones del periclitar del líder político puede hallarse en su indecisión, su falta de compromisos claros. ¿Por qué?, porque las decisiones pueden ser erróneas, impopulares y esto se paga: Si el líder político no puede garantizar línea programática alguna -debido al atenazamiento que ejercen sobre ellas los resultados de la globalización, del imperialismo de la economía, etc.-, delega en el técnico, que puede ser fácilmente removido (como si fuese una parte de la maquinaria política) y acusado de torpeza.

La irresponsabilidad del liderazgo político es clara según esta visión, porque se niega a ser responsable. Incapaz de decidir, el líder político postmoderno se escuda en la falta de "competencias"; en los rumbos incontrolables de la economía; en las herencias de gobiernos pasados; en la falta de colaboración de la oposición 
para lograr el bienestar y paz común; hasta en la falta de colaboración de los mismos ciudadanos. Ante el temor de tomar medidas impopulares o provocar el enfado de los grupos de presión, su coraza son los tecnócratas. Así visto, el líder político no es debilitado, sino que se debilita a sí mismo por no afrontar sus responsabilidades.

Por este camino, se puede beatificar al tecnócrata, como una especie de mártir esclavizado por el político declinante. En este sentido se expresa Pierre Laroque:

"La gran mayoría de los altos funcionarios no desean sustituir a los ministros en la definición de una política gubernamental. Su mayor deseo es ver al ministro con quien colaboran definiendo una política de líneas claras y precisas, duradera y coherente, a cuya aplicación se consagraría, en tal caso, lealmente. A falta de esta política, sería injusto acusarles de que traten de convencer al Gobierno de que adopte el programa que ellos creen eficaz" ${ }^{48}$.

Meynaud reafirma, en parte, las sentencias de Laroque:

"En varias ocasiones, ciertos funcionarios franceses se han referido al carácter desmoralizador del vacío político en el que se encontraban obligados a trabajar: el inmovilismo, el rechazo de las decisiones, la falta de visión de futuro han sido características de los políticos, por lo que difícilmente podríamos contradecir este juicio" ${ }^{49}$.

Así visto, el tecnócrata, que no dispone de los medios de defensa propios de los políticos (Parlamento y media), es una víctima, víctima de las insuficiencias y debilidades del político. Pero el mismo Meynaud no corrobora enteramente estas últimas afirmaciones, como cuando en el proceso de politización y relación con el poder del que disfrutan los tecnócratas, se observa cómo acaban por alejarse de esa visión idílica de empleados sumisos y castigados por el mal gobierno de su amo.

En definitiva, el liderazgo político declina y, con él, el líder político porque, entre otras razones, plantea una serie de soluciones para la mejora del funcionamiento de las organizaciones en las que los técnicos adquieren protagonismo. Además, al desviar sus responsabilidades (para no deteriorar su imagen) acaba dependiendo de ellos. Los líderes políticos son víctimas de las soluciones que emplean. Pero, además, el técnico, como especialista que es en un área de conocimiento positivo, no puede apreciar la totalidad (ahora se dice globalidad) del hecho técnico, mucho menos aún lo que suponen otras áreas que no son eminentemente técnicas. A fin de cuentas, como Durkheim decía, hay un contenido moral en la sociedad, ese que no puede ver el técnico: toda esa serie de factores (como comenta Victoria Camps ${ }^{50}$ ) que pueden desencadenar disfuncionalidades, consecuencias imprevistas (la fábula mandevilliana se repite) y, sobre todo, inconvenientes para la sociedad desde el punto de vista de otros valores.

Llegados a este punto, podemos colegir que, en el campo de las decisiones políticas, éstas tienden a ser tomadas desde perspectivas y razones que parecen tener poco de políticas. Entremos, por lo tanto, en la parte más crítica de esta 
exposición, que se centra sobre los problemas de la ideología, el liberalismo, la democracia, la tecnocracia y la economía.

Entre los rasgos que definen a la postmodernidad, es bien conocido, como hemos citado, el debate sobre el desgaste de las ideologías y el ocaso de los Estados nacionales e Instituciones construidas en la modernidad. Esto no quiere decir que las decisiones ahora se tomen siempre desde las grandes empresas, pero sí sabemos de la presión que ejercen las mismas y todo el capitalismo financiero, directa o indirectamente sobre los Estados. A su vez, los organismos supranacionales (Unión Europea, por ejemplo) dependen de la misma medida de las fluctuaciones del mercado y de los supuestos "ciclos económicos". En este sentido, la actividad económica y, sobre todo, la financiera, han trascendido los ámbitos nacionales y campan, como un Prometeo desencadenado a sus anchas. La cuestión es que la economía, tal como se entiende hoy en día, es fundamentalmente tecnocrática, ultraliberal y conservadora. A fin de cuentas, no son los Estados quienes regulan a la sociedad (sin que esto tenga que ser por fuerza bueno) sino el mercado (lo que no es realmente bueno).

Bajo las razones tecnocráticas, económicas y liberales, late un pulso ideológico enmascarado. Liberadas de su referente (el socialismo), se filtran por los poros del entramado político y social y lo desintegran como el agua destruye a las rocas. Sobre este punto quiero detenerme en esta parte de mi discurso: sus propuestas son ideológicas y políticas, aunque se tilden de lo contrario, y con ideología hay que combatirlas. Cuando el liberalismo nos dice que no puede haber una política diferente, nos dice que la ciencia (económica) y el sentido común (sujeto a las leyes del mercado), dictan un modo de hacer (best way) política.

El liberalismo actual (neo, ultra, etc.) es liberalismo conservador (si queremos lo podemos tildar de neo también) y tecnocrático que, hábil y fiel a su condición postmoderna $^{51}$, se estetiza y se cubre de adornos: defensa de la libertad (empresarial), de los derechos de los ciudadanos (de los consumidores), política centrista-democrática (responsable, "aideológica"). Ni siquiera admite su condición conservadora -de derecha-, sino que se presenta como una melange (postmoderna pura) decorada de democracia, algo que, históricamente no le pertenece, como veremos.

¿Y por qué no puede haber otra opción política, otra manera de hacer política? Porque la Historia y los números cantan.

La Historia ha demostrado la inviabilidad no sólo de otros sistemas políticos, sino del empleo de la ideología. Los grandes relatos en la postmodernidad, como dice Lyotard, se han demostrado caducos o inútiles, han generado tensiones y conflictos, y no han llevado al hombre a aquél estadio de la felicidad que prometía el progreso, esa especie de providencia secularizada por la razón, razón que ha muerto. La ética de la convicción muere y sólo nos queda la ética de la responsabilidad, olvidando que ambas son necesarias, pues juntas garantizan la libertad y la igualdad. ¿Y los números? Hemos dicho que cantan. 
Las grandes magnitudes económicas (la macroeconomía), trascienden su marco como agentes económicos y no sólo explican la sociedad y la política, sino que las guían. Así, pues, la política social queda siempre sometida (ni siquiera regulada) por la política económica.

El discurso del darwinismo social no dista mucho del discurso del liberalismo hoy en día. Porque, aunque se nos hable de un liberalismo democrático, este jamás ha existido, el liberalismo nunca ha sido democrático. En todo caso, y durante algún tiempo, liberalismo y democracia establecieron un acuerdo que parece romperse. La tradición liberal, como nos dice Göran Therborn ${ }^{52}$, no fue democrática desde John Locke en adelante. Y la democrática, desde Winstanley, Rousseau y Robespierre, no fue liberal, como nadie duda, o no debería hacerlo, de que el movimiento obrero fuese alguna vez liberal, más bien al contrario. De hecho, entre los primeros socialistas utópicos, había liberales desencantados (como dice el profesor Lucas Verdú), caso de Sismondi.

Lo que ocurrió fue que se estableció un matrimonio entre liberalismo y democracia tras la Segunda Guerra Mundial (1947-1963) en la que sus representantes aceptaron dar algo de cada uno de ellos (aceptación del keynesianismo y del Welfare State/aceptación de la propiedad privada y del libre mercado), a partir de entonces, las tensiones no han cesado y hoy no sabemos cuánto tiempo más convivirán liberalismo y democracia. Sobre todo desde el momento en que la ciudadanía, nexo de unión entrambas, ha visto cómo se debilitaban sus derechos, pues la sociedad capitalista (con Hayek a la cabeza), no puede tolerar el despilfarro que supone mantener los derechos sociales, pero la democracia, si quiere seguir llamándose así, no puede perderlos.

En el liberalismo late una semilla reaccionaria, es incluso capaz de vender su propia libertad (ya lo dijo Fromm) con tal de no perder su bien más preciado: la propiedad. Cuando decimos que no dista tanto del darwinismo social lo hacemos porque éste se presentó como reacción al marxismo y al activismo obrero. Desde postulados pseudocientíficos concluía que el liderazgo de la humanidad correspondía a aquellas manos capaces, no a los que no supieran o no pudiesen adaptarse a la lógica del progreso (entendido como acumulación, lo que no garantiza forzosamente la apertura de la senda hacia la felicidad humana). A éstos, habría que dejarles en el camino o acelerar su desaparición.

El liberalismo es la libertad para unos, pero no para todos; es la libertad para los países desarrollados, pero sólo para ellos. En su carácter estetizante se viste de democracia, pero se argumenta económica y técnicamente.

No hay cuestión moral ninguna, sino científica. Mas nosotros tenemos bien claro que las ideologías son ideologías aunque se disfracen y, tras el darwinismo había una clase (burguesa) con ideología reaccionaria que, burdamente extrapolaba las supuestas pautas evolutivas del reino animal al reino de las cosas humanas. En el discurso técnico-economicista habitual, el que invalida cualquier discrepancia 
paternalmente, late la ideología, no digo en este caso de una clase burguesa, pero sí una ideología igualmente reaccionaria, en la que la desigualdad es un hecho, un "mal menor".

Imanol Zubero nos dice:

"¿Por qué discrepan los economistas?...al principio de la actividad mediante la que los economistas intentan explicar la realidad no están los hechos, sino una determinada teoría sobre la forma en que se produce la creación de valor en una sociedad determinada...En otras palabras, los economistas discrepan en sus análisis de la realidad porque sus respectivos puntos de partida, sus perspectivas teóricas son distintas"

Ya Comte dio un carácter religioso a su sociología, donde las verdades eran descubiertas por el método científico y así pasaban a convertirse en dogmas, cosa que ahora parece ocurrir de nuevo en el discurso neoliberal-economicista. Pues bien, la teoría determina aquello que podemos observar, y la teoría, toda teoría, mana de nuestra visión de las cosas que, por muy depurada que sea, siempre es ideológica. La ciencia no está libre, en ningún momento, de los valores, no existe la neutralidad y objetividad puras ${ }^{54}$. Así, pues, y siguiendo con Zubero, el problema se centra en que la economía no se enseña como una manera de aprender de qué modo podría funcionar el mundo, sino como una serie de verdades acerca de cómo funciona. Los economistas se vuelven arrogantes cuando olvidan que su actividad científica y académica está sustentada sobre juicios de valor.

Ya sabemos que la desaparición de la política, supone el triunfo del totalitarismo. La política, antes irresponsable, ahora es inútil y, en vez de ser eliminada por un autocratismo de uno u otro género, es sofocada por su tecnificación, investida de la razón técnica superior. La debilitación de la política supone la desaparición de su discurso, de la discrepancia y de la opinión ante las nuevas verdades técnico-económicas. Los nuevos sabios son los analistas del mercado que, mediante su discurso inapelable, crean un clima de opinión que, por repetido, se vuelve verdadero. A propósito de lo que decimos, cita Zubero a Pierre Bourdieu de la siguiente manera:

“...una de las bazas del pensamiento neoliberal es que se presenta como una gran cadena del Ser: Igual que en la vieja metáfora teológica, en la que en un extremo aparece Dios, y después se llega a las realidades más humildes por medio de una serie de eslabones, en la cima de la nebulosa neoliberal aparece, en lugar de Dios, un matemático, y en su base, un ideólogo que no sabe nada de economía, pero que puede hacer creer que sí gracias a un ligero barniz de vocabulario técnico" ${ }^{55}$.

¿Cuántos que presumen de no hacer política, de no poseer ideología, hacen política y enmascaran su ideología?. Es posible que, incluso, no aprecien que la tienen.

No se trata tampoco de demonizar ni emitir juicios maniqueos. Sería una grave injusticia afirmar que todo economista es un liberal reaccionario y que todo pensamiento economicista es una mentira expresada por la boca de la clase 
dominante. Tampoco el empleo de la técnica debe ser desdeñado o negado (no en vano, hemos comenzado este artículo recordando la importancia capital de la tecnología en el desarrollo de la especie humana).

No sólo existen economistas serios e intachables, sino que la ciencia económica es un instrumento más, dentro del ámbito de las ciencias sociales, que debe coadyuvar al conocimiento de la sociedad y a su mejora, pero no puede convertirse en razón matemática. Sobre todo cuando la formación de sus representantes posee una base tan abstracta y teórica que les hace separarse del propio mundo que estudian: "confundiendo las cosas de la lógica con la lógica de las cosas" $"$ "5bis

De hecho, prácticamente nunca han podido someter a verificación experimental los modelos teóricos sobre los que se apoyan y en los que creen con fe ciega. Por otro lado, menosprecian aquellos análisis que no tienen la "pureza" (sigo parafraseando a Bourdieu) de sus juegos matemáticos.

En la instauración del liberalismo (que ocurrió de manera lenta e imperceptible) se ha producido la paradoja de que, lo único que lo hace humano es aquello contra lo que lucha: tanto el Estado como todas las redes de solidaridad y protección social. Y lo peor es que la economía acaba por servir fielmente a los intereses de tal ideología cuando contribuye a que todo se comercialice, hasta la propia cultura.

Así, pues, nuestro problema se manifiesta cuando las herramientas que creamos nos controlan y salen de su marco invadiendo otras esferas que no les pertenecen. Como es el caso de la política -y en la política-, cuando los partidos y sus líderes abandonan el discurso ideológico y pierden sentido conviertiéndose, aún más, en empresas. Una ética de la convicción abandonada a sí misma puede provocar desastres, pero una ética de la responsabilidad liberada a sí misma crea opresión. Ambas, como hemos dicho (como dijo Weber), deben equilibrarse.

El eminente sociólogo galo, Alain Touraine, publicó hace poco más de un año un libro titulado: ¿Cómo salir del liberalismo? ${ }^{56}$ en el que, preocupado por el rumbo de las actuales políticas económicas y sociales, del ideario en conjunto de nuestras sociedades, se propone buscar nuevas salidas. Touraine, que siempre busca la verdad, acusa al pensamiento liberal, pero también a los argumentos demagógicos que existen en la izquierda, así como a quienes, bajo un pesimismo profundo, proponen solo la defensa de las instituciones. No puedo dejar de afirmar que Touraine es incómodo para todos ellos, más aún cuando uno cree haber cometido varios o muchos de los errores que el maestro galo denuncia en este libro. Pero, aparte de tomar conciencia de que nuestra actividad como profesionales de la docencia (no me atrevo a decir "intelectuales"), es la de explicar, criticar y denunciar, también es la de reconocer nuestros errores y esforzarnos por buscar nuevas propuestas que, curiosamente, pueden encontrarse en la propia ciudadanía, la misma que defendemos pero que, en ocasiones, minusvaloramos desde una cierta suposición de "superioridad" intelectual. 
Para Touraine, el reto de los Estados democráticos se encuentra en dar mayor salida y eco a los nuevos actores sociales que están reivindicando derechos e identidades colectivas. Para ello será necesario desenmascarar ciertos clichés y etiquetas de moda "que confieren una apariencia de consenso general tan poderoso que se convierte en verdad social" (parafraseando la anterior cita de Zubero):

"Y es que, mientras estemos inmersos en el discurso de la mundialización -o globalización, que viene a ser lo mismo-, estaremos privados de la demostración concreta de nuestra impotencia social y política en relación con lo que sería necesario llamar por su verdadero nombre, la ofensiva capitalista. Nada, en efecto, da pie para afirmar que, de golpe, las políticas sociales se han convertido en imposibles, que las políticas industriales no tienen más que efectos negativos, que la tecnología se encuentre al servicio de los intereses financieros dominantes o que el declive de las antiguas formas de gestión administrativa de la economía no pueden conducir más que al triunfo del capitalismo salvaje" ${ }^{56}$.

Debo decir que, humildemente, discrepo en cierta medida con Touraine, pues mi postura es posible que sea más pesimista que la de él, aunque estoy dispuesto a dejarme convencer. En el actual orden de cosas, el papel de la ciudadanía y de las instituciones políticas heredadas de la modernidad, está muy debilitado. Y, aunque necesarias de transformación, debemos partir de ellas.

El maestro galo afirma que, en la tarea de comunicar y potenciar los movimientos sociales, los intelectuales poseen una responsabilidad insoslayable para transformar la protesta en la formación de estos nuevos actores e, indirectamente, de la creación de nuevas políticas económicas y sociales. Si la situación de estos intelectuales es complicada en Francia, en donde se dio una especie de "silencio de los intelectuales", qué podemos decir de España, donde no poseemos la tradición que sí tienen nuestros vecinos del norte. Más aún, el propio Touraine teme que este análisis crítico quede abortado ante una posible indiferencia de los poderes políticos ante las luchas sociales:

“...desconfiando de ellas y contentándose con la puesta en marcha de políticas centristas que combinan la gestión liberal de la economía con la sola preocupación por el orden y la seguridad pública. Si la mayoría elegida en el gobierno no siente el deber de representar a los sectores más desprotegidos de la sociedad ¿cómo nos podemos sorprender de que éstos se dejen seducir por los que profetizan fracturas y catástrofes?".57.

El actual Gobierno de Aznar tiene ante sí tres años más de mayoría absoluta. Ante esta última reflexión, sólo podemos esperar una sensibilidad por parte del mismo que nosotros creemos dificultada por su propia orientación ideológica y su reciente mayoría. Espero equivocarme.

Estamos ante una sociedad excluyente, y sé que no digo nada nuevo con esto, pero conviene recordarlo. Una sociedad excluyente en los ámbitos de la cultura, la política, la economía, la vivienda y el empleo que corroboran el famoso concepto ya mencionado de Peter Glotz: "Sociedad de dos tercios". 
Sé que las cifras de empleo nos ofrecen unos datos que el último gobierno de Aznar (y suponemos que así ocurrirá con éste que hemos comenzado), ha mostrado como éxitos indiscutibles de su gestión tras cuatro años, ahora no tan claros y amenazados por una inflación sorpresa. Se ha llegado a decir que en esta década se llegará al pleno empleo (un debate que ya está en la UE). Bella obsesión que transforma en empleo cualquier cosa, tanto, que "empleo" y "parado" son dos conceptos que ahora convendría redefinir a la baja. Al final, como James Petras y Steve Vieux dicen, el liberalismo socava los valores sobre los que se sustenta: el individuo y la familia (incluyen también la conciencia democrática). En concreto, esta última, que incluso se transforma de "nuclear" a "monoparental" (no olvidemos, con menores a su cargo), es la que soporta, cada vez más reducida y debilitada, los efectos de la sociedad de riesgo en la que vivimos. Y en cuanto al individuo, su pertenencia a la sociedad, pierde importancia, con lo que la soberanía de los Estados queda erosionada.

Será tiempo que los liberales recuperen más a Locke (al cual nunca se recuerda y es uno de los pocos nexos de unión y de diálogo posible del liberalismo con la Democracia) que a Smith, y que la poiesis (efectividad desnuda) abra camino a la praxis (efectividad guiada por una ética). En efecto, John Locke (1632-1704) es anterior a Adam Smith (1723-1790) $)^{59}$, mientras el segundo es el padre del liberalismo económico, el primero lo es del político. Las libertades económicas deben construirse después de las políticas, y no al revés, puesto que una libertad de empresa sin referencia de la libertad política, es una creatura desatada que se vuelve contra su creador y contra aquello que la sustenta (como así nos dicen Petras y Vieux).

Retomando el hilo argumental, nos encontramos ante la certeza de que una política tecnocrática, constreñida por la razón económica, genera exclusión y acaba por considerar la desigualdad como un hecho o, peor, como un mal necesario que se soluciona mirando hacia otra parte, olvidando o aplacando la conciencia con prácticas benéfico-asistenciales. Los derechos sociales, sobre los que se construye la ciudadanía, están amenazados, y están amenazados porque se ha desrregulado la esfera política:

"En la actualidad la tendencia más fuerte apunta hacia una forma de liberalismo post-democrático, en gran parte dirigido por los mercados financieros globales, con un sistema social caracterizado por diversas formas de exclusión socioeconómica e informativa, que se mantiene unido por redes y sueños de dinero y que se legitima por el ineludible poder del mercado y mediante plebiscitos mediatizados" $"$.

La postura de Therborn parece oscurecer más el panorama cuando afirma que el liberalismo de Norteamérica y Europa Occidental (que, como hemos visto, califica de post-democrático), no es probable que suprima, o subvierta, las instituciones democráticas. En todo caso, la democracia acabará por extinguirse. 
Las asociaciones y la gente política, en tal escenario, serán marginadas y no se les hará absolutamente ningún caso antes que ser asediadas o atacadas. La suave sumisión de hierro que ejerce el liberalismo elimina la política y el pensamiento, sustituidos por la Verdad de sus dogmas tecno-económicos, responsables. Todo esto se traduce en una nueva política (¿post-política?) representada por un liderazgo político (¿post-liderazgo?) como el que Jones y Hudson investigaron sobre John Major, sólo que más eficaz. El país será gobernado como una empresa (y no olvidemos, como apunta Lindblom, que las grandes empresas se adaptan mal o en absoluto a la teoría y visión democrática), en la que los ciudadanos, como sabemos, se convierten en consumidores, sin movilización posible. ¿Seguiremos entonces los españoles dando tal alto grado de legitimidad a la democracia como ahora?.

El neoliberalismo, como apunta Bourdieu, es un programa político apoyado en una teoría económica que se piensa como una descripción científica de lo real:

"Esta teoría tutelar es una pura ficción matemática basada, desde su origen, en una formidable abstracción... De esta especie de pecado original, inscrito en el mito walrasiano de la 'teoría pura', se desprenden todas las carencias y todos los incumplimientos de la disciplina económica, y la fatal obstinación con que se aferra a la oposición arbitraria que hace existir, por su mera existencia, entre la lógica propiamente económica, basada en la concurrencia y portadora de eficacia, y la lógica social, sometida a la regla de la equidad".

Esta "teoría" (como sigue diciendo Bourdieu), desocializada y deshistorizada, se ha convertido en un "discurso fuerte" contra el que es difícil combatir y que ha comenzado a destruir las medidas políticas y estructuras colectivas que obstaculizan el avance del mercado.

A pesar de ello, la ciudadanía, la sociedad, como la vida misma, se abre camino. Bien a través de esos movimientos y actores sociales que cita Touraine (y, en el fondo, todos los críticos del liberalismo sagaces), bien a través de una vuelta a una política ideológica declarada, comprometida (lo que no significa irresponsable), en la que los intelectuales puedan restablecer la unión entre vida social y política y los políticos-declarados-, recojan tal compromiso.

No olvidemos que "política" viene de polis, aquél lugar en el que la vida perfecta, libre, se conseguía a través de la palabra, expresada como forma de distinguir lo bueno de lo malo, lo justo de lo injusto, combinando los intereses individuales con los de la comunidad. Y esa palabra adquiría sentido a través del logos, logos no reducible sólo a la esfera económica, tecnocrática. 


\section{NOTAS}

${ }^{1}$ Los vocablos cultos Téchne, Technikós eran utilizados habitualmente por los eclesiásticos que referían a "maña", "astucia". GRUPO ESPAÑOL: "Técnica", en Diccionario de Ciencias Sociales, p. 1005.

${ }^{2}$ Lucas Verdú, Pablo: Principios de Ciencia Política. Tomo III. Tecnos, Madrid 1979, pág. 208.

${ }^{3}$ Como se puede observar claramente en la obra de Malinowski, aunque también, más recientemente en la obra de Haeffner: Antropología filosófica. Herder, Barcelona 1986, así como, y de forma clarísima, en Arnold Gelhen y su Antropología Filosofica (trad.Carmen Cienfuegos). Paidós, Barcelona, 1993.

${ }^{4}$ Como se puede observar en su conocida obra: El puesto del hombre en el cosmos, (trad. José Gaos). Losada, Buenos Aires, 1938.

Ortega y Gasset, José: Meditación de la técnica (estudio y notas por Jaime de Salas y José María Atencia). Santillana, Madrid, 1997.

${ }^{6}$ En GRUPO ESPAÑOL: Op.Cit. pág. 1006.

${ }^{7}$ Capanna, Pablo: La tecnarquía. Barral, Barcelona, 1973, pág. 26.

${ }^{8}$ Burns, T. en GRUPO ESPAÑOL: Op.Cit. pág. 1009.

${ }^{9}$ José B. Terceiro: Del homo sapiens al homo digitalis. Alianza, Madrid, 1996, pág. 29.

${ }^{10}$ Giner, Salvador en: Giner, Salvador; Lamo de Espinosa, Emilio y Torres, Cristóbal (eds.): Diccionario de Sociología, Alianza, Madrid, 1998, pág. 772.

"Galbraith, John Kenneth: El nuevo Estado industrial (trad. Manuel Sacristán). Ariel, Barcelona, 1984.

"(bis): Convendría aclarar el concepto "tecnoestructura", que arranca de John Kenneth Galbraith. El viejo economista, ampliando el análisis de Burnham sobre la "revolución de los managers"(aquellos que tomaron, según este último, el mando en las empresas privadas en lugar de los capitalistas. Véase la cita 13), llamó "tecnoestructura" a la dirección colectiva que asocia a la marcha de la empresa a todos los que poseen informaciones necesarias en esa dirección. Este análisis ha sido matizado por Maurice Duverger: Las dos caras de Occidente (trad. Ismael-Elías Pitarch). Ariel, Barcelona, 1974. Duverger opina que Galbraith minimiza el papel de los capitalistas y que éstos tienen aún la última palabra. De hecho, la tecnoestructura sería un estrato por debajo de los grupos financieros, empresas gigantes, holdings, etc., así como de la élite del poder de firmas gigantes, bancos de negocios, etc.: "Esta tecnoestructura corresponde, en la oligarquía del neocapitalismo, a los príncipes de sangre real de la antigua aristocracia". op, cit., pp. 167-168. El maestro galo introduce otro concepto, el de "tecnodemocracia" que ha empujado a la creación de vastas organizaciones colectivas (empresas gigantes, partidos de masas, grupos de presión poderesos, etc.).

${ }^{12}$ Sobre un razonamiento similar se sustentan el neodarwinismo y neoconservadurismo. 
${ }^{13}$ Burnham, James: The managerial Revolution: What is happening in the world. Greenwood Press, Westport, Conneticut, 1972.

${ }^{14}$ García-Pelayo, Manuel: Burocracia y Tecnocracia. Alianza (segunda reimpresión), Madrid, 1987, pág. 33. En esta misma página recoge otras dos definiciones: "Remoción del político por el técnico" y "Cuando de una u otra manera el técnico consigue asegurarse la última palabra y cuando ha logrado la facultad de resorte último", Ibid.

${ }^{15}$ Caso de: "La tecnocracia representa al alto personal del Estado y de las empresas (privadas y públicas) que ocupa los puestos directivos en los países industriales sin que su papel dominante se deba a la elección o a un título de propiedad". Cazeneuve, Jean y Victoroff, David (dirs.): La sociología, Ediciones Mensajero, Bilbao, 1985, pág. 499.

${ }^{16}$ Cazeneuve, Jean y Victoroff, David: op.cit., pág. 500.

${ }^{17}$ Para este autor la tecnarquía apunta al plano ontológico pues señala la técnica instaurada como principio. Es el hacer convertido en principio del ser, la actividad transformadora puesta como fundamento del mundo, de la existencia y del pensar frente a la tecnocracia que destaca el kratos o poder, lo que señala el carácter político de la dominación.

${ }^{8}$ No debemos olvidar el carácter conservador y técnico del término. En este momento lo utilizo para reforzar la tendencia inmutable de la Tecnarquía tal como la categoriza Capanna.

${ }^{19}$ Capanna, Pablo: op.cit. pp. 121, 122.

${ }^{20}$ García-Pelayo, Manuel: op.cit. pp. 62 y ss.

${ }^{21}$ Tampoco conviene olvidar que tales concursos son bastante excluyentes. El caso de la ENA, en Francia, es claro ejemplo de lo que digo, como no es menos cierto que la casi totalidad de líderes políticos galos estudiaron en esta Escuela de Administración. ${ }^{22}$ Tofller, Alvin: El shock del futuro (trad. J. Ferrer Aleu). Plaza y Janés, Barcelona, 1993.

${ }^{23}$ García-Pelayo, Manuel: op.cit. pág. 52.

${ }^{24}$ Es decir, dentro de las democracias contemporáneas, se observa un tercio de la población que no participa, excluido e incapacitado para acceder a la cultura, educación, política, economía, etc. Cfr. de Lucas y Murillo de la Cueva, Fernando: "Sociedad de dos tercios y Servicios Sociales" en II Congreso de Escuelas Universitarias de Trabajo Social: Globalización y Trabajo Social. Escuela Universitaria de Trabajo Social, UCM, Madrid, 1998, pp. 310 y ss.

${ }^{25}$ Con respecto al conocido asunto de Seguridad Social y el crecimiento económico, el jefe de la sección de macroeconomía de The Guardian, Larry Elliot, remite una serie de datos interesantes. "Holanda gasta, en comparación con Estados Unidos, un 14\% del PIB más en Seguridad Social. Por lo tanto, si los partidarios de los recortes presupuestarios tienen razón, esta diferencia tendría que reflejarse en un mayor crecimiento de la nación americana. Sin embargo, la economía de ambos 
países creció a un ritmo casi idéntico durante el último ciclo económico (19821992): en EEUU, un 2,9\% anual y en Holanda un 2,7\%". Apoyándose en un estudio publicado en New Economy de Tony Atkinson sobre 10 países y su relación entre Seguridad Social y actividad económica, llega a las conclusiones siguentes. En dos de ellos un alto gasto social tiene un impacto irrelevante sobre la economía; en cuatro frena el crecimiento y, en otros cuatro, genera mayor actividad. Elliot, Larry: "El palo desplaza a la zanahoria", en El Mundo, 2 septiembre 1996.

${ }^{26}$ Capanna, Pablo: op.cit., pág. 164.

${ }^{27}$ García-Pelayo, Manuel: op. cit., pág. 61. García-Pelayo, citando a Kosík, recoge los rasgos principales del "político manipulador". A saber: "sustituye el pensamiento crítico por una conciencia sistémica falsa que funciona por frases, y por un sistema de equívocos y de mistificación generalizadas... reduce todo a su nivel, a la esfera de la técnica, de lo útil y del efecto inmediato. Consecuentemente, piensa la realidad con esquemas de manipulación, de utilitarismo y de dominación, pues sólo considera real aquello que es dominable, manipulable y útil... la política es para él 'un sistema de manipulaciones generales'... Es esclavo de lo inmediato, del tiempo presente ante el que meramente reacciona... vive al día. Es incapaz de rebasar el horizonte del sistema instituido a través de sus acciones y al que él mismo se sacrifica... no puede entender más que aquellas cuestiones que caen dentro de su horizonte... Sólo puede resolver algunos problema sociales y determinadas áreas de crisis, pero es impotente frente a una realidad que rebase su horizonte... puede tratar de superar crisis económicas y constitucionales, pero queda perplejo ante las crisis morales... aquéllo que afecta existencialmente a un pueblo y a unos hombres", Ibid.

${ }_{28}^{28}$ García-Pelayo, Manuel: op.cit., pp. 75, 76.

${ }_{30}^{29}$ Ibid.

${ }^{30}$ Fernández de la Mora, Gonzalo: El crepúsculo de las ideologías. Rialp, Madrid, 1965, pp. 202 y ss. Obra a la que el profesor Lucad Verdú responde en Principios de Ciencia Política, vol. I. Tecnos, Madrid 1975, diciendo que las ideologías no han muerto, sino debilitado por el triunfo de la tecnificación y el ocaso del carisma. ${ }^{31}$ Touraine, Alain: Crítica de la modernidad (trad. Maruro Armiño). Temas de Hoy, Madrid, 1993, pp. 192-193.

${ }^{32}$ Touraine, Alain: op.cit.,pág. 139. También nosotros nos hemos referido al problema de la crisis de la racionalidad en el pensamiento postmoderno, véanse los capítulos 1, 2 y 8 de de Lucas, Fernando (coord.): Lecciones de Sociología General. Editorial Centro de Estudios Ramón Areces S.A., Madrid, 1999.

${ }^{33}$ Lucas Verdú, Pablo: Principios de Ciencia Política (Estructura y dinámica políticas), tomo II ( $3^{\text {a }}$ edición corregida). Tecnos, Madrid, 1979, pág. 137

${ }_{35}^{34}$ Lucas Verdú, Pablo: op.cit., pág. 139.

${ }^{35}$ Lucas Verdú, Pablo: "Ciencia Política para neoconservadores", en Revista de Estudios Políticos, Instituto de Estudios Políticos, Madrid, 1965, pp. 207-214.

${ }^{36}$ Meynaud, Jean: La tecnocracia: ¿Mito o realidad? (trad. José Blasco). Tecnos, 
Madrid, 1968, pág. 282. Es, decir, modificaciones hacia la institucionalización política de la tecnarquía.

${ }^{37}$ Meynaud, Jean: op.cit., pág. 285. Meynaud transcribe las reflexiones de Armand y Drancourt sobre estos asuntos. Cuando se refiere a $* 2$ se refiere a "la posibilidad de abundancia". Ibid.

${ }^{38}$ Lucas Verdú, Pablo: op.cit., pág. 208.

${ }_{40}^{39}$ Lucas Verdú, Pablo: op.cit., pág. 211.

${ }^{40}$ Minkenberg, Michael y Inglehart, Ronald: "Neoconservatism and Value Change in the USA: Tendencies in the Mass Public of a Postindustrial Society", en John R. Gibbins (ed.): Contemporary Political Culture. Politics in a Postmodern Age. Sage, Londres, 1990, pág. 88.

${ }^{41}$ Turner, Bryan S.: "From postindustrial society to postmodern politics: the political sociology of David Bell”, en Gibbins, John R.: Op.Cit., pág. 209.

${ }_{43}^{42}$ Lucas Verdú, Pablo: op.cit., pp. 212, 213.

${ }^{43}$ Habermas Jürgen: "Theory and practice in a scientific civilization", en Connerton, Paul (ed.): Critical Sociology: Adorno, Habermas, Benjamin, Horkheimer, Marcuse, Neumann. Selected Readings. Penguin Books, Harmondsworth, Middlesex, 1976, pp. 330-347.

${ }_{45}^{44}$ Marcuse, Herbert: "Repressive tolerance", en Connerton, Paul: op.cit., pág. 310. ${ }^{45}$ Aunque la misma Unión es la creadora de un tipo de liderazgo que comienza y se agota en sí mismo. Este es el caso de Jaques Delors, primer presidente de la Comisión (1985-1995) y que, según Helen Drake, representó un estilo de liderazgo, que ella denomina "supranacional", con sus convenientes dosis de tecnocracia, moralismo, paternalismo, pedagogía, etc. Delors, que sirvió al gobierno gaullista de Jaques Chaban-Delmas a finales de los años sesenta y más tarde fue Ministro de Estado de los socialistas, a los que se unió en 1974, no fue elegido nunca por el pueblo europeo, pero se convirtió en presidente de los europeos. "Dotado de un perfil de primera cabeza del Estado pero con un rol de broker". Drake, Helen: "Political Leadership and European Integration: The Case of Jaques Delors", en West European Politics. Frank Cass. Londres, volumen 18, n 1 , Enero 1995, pág. 147. Para Drake, el final del mandato de Delors fue el final de tal tipo de liderazgo.

${ }^{46}$ Jones, Philip y Hudson, John: "The quality of political leadership: A case study of John Major", en British Journal of Political Science. Cambridge University Press, abril 1996, volumen 26, parte $2^{\text {a }}$, pp. 229-244. Por calidad del liderazgo entienden estos autores a las percepciones de liderazgo "en los ojos del electorado".

${ }_{47}^{4}$ Jones, Philip y Hudson, John: op.cit., pág. 244.

${ }_{48}^{48}$ Laroque, Pierre; en Meynaud, Jean: op.cit., pág. 143.

${ }^{49}$ Ibid.

${ }^{50}$ Camps, Victoria: "Educación y democracia posliberal” en Tezanos, José Félix, op.cit.

${ }^{51}$ Parafraseo el título del famoso libro de uno de los profetas de la postmodernidad, 
Jean Françoise Lyotard: La condición postmoderna (trad. Mario Antolín Rato). Cátedra, Madrid 1996.

52. Therborn, Göran: "Más allá de la ciudadanía: ¿Democracia post-liberal o liberalismo post-democrático?". En Tezanos, José Félix (ed.): La democracia post-liberal. Sistema, Madrid, 1996, pp. 43-58.

. Zubero, Imanol: "Otras visiones sobre empleo y economía”. En Inguruak, Euskal Soziologia-Elkartean Boletina, n 61. Bilbao, 2000, pág. 6.

${ }^{54}$. Como hablo sobre este asunto en la introducción y el último capítulo de ya citados de, de Lucas, Fernando (coord.): op.cit.

. Zubero, Imanol: ob. cit. pág. 7. En concreto, tal cita proviene de la obra de Bourdieu, Pierre: Contrafuegos. Reflexiones para servir a la resistencia contra la invasión neoliberal (trad. Joaquín Jordá). Anagrama, Barcelona 1999.

${ }_{556 i s}$ Bourdieu, Pierre: op. cit. pág. 145.

${ }^{56}$. Touraine, Alain: ¿Cómo salir del liberalismo? (trad. Javier Palacio Tauste). Paidós, Barcelona 1999.

${ }_{58}^{58}$. Touraine, Alain: op. cit. pág. 15.

${ }^{58}$.Petras, James y Vieux, Steve: "Neoliberalismo y vida cotidiana", en Diario El País, Madrid, 27 de marzo de 1996. Entre otras cosas, dicen lo siguiente: "El ethos del neoliberalismo demanda todo o lo mejor del tiempo de cada trabajador: frecuentes cambios del puesto de trabajo, mayor disponibilidad y aumento del número de miembros familiares que deben ponerse a trabajar. El resultado es la reducción al mínimo del tiempo de calidad que se comparte en familia; a ésta o a la pareja les queda un espacio de tiempo residual caracterizado por el agotamiento, las tensiones y la alienación que conduce a 'olvidarse' o 'relajarse' buscando el aislamiento, sin deseos ni energía para iniciar relaciones afectivas" y más adelante, con respecto a la reducción general de los salarios según la lógica neoliberal, comentan sobre los jóvenes y las familias: "La dependencia de los padres, la falta de espacio, la pérdida de autonomía y los ingresos limitados entrañan un cierto tipo de adolescencia prolongada en la que se hace inevitable el conflicto... La desaparición del empleo a tiempo completo significa que se dispone de dinero para asistir a un concierto de rock, pero no para un piso; para una noche de diversión, pero no para mantener una relación estable y duradera; para salir de bares con los amigos durante el tiempo libre, pero no con amistades forjadas en un lugar de trabajo estable".

${ }^{59}$. No olvidemos que Smith, como buen escocés, traducía un pensamiento netamente optimista que descargaba de cinismo la famosa "Fábula de las abejas" de Bernard Mandeville. Ese pensamiento no pudo ver que su "mano invisible" se convirtió en "fatalidad". Así lo denunciaron liberales desencantados como Sismondi y todos los socialistas utópicos, como también, y de forma genial, Max Weber en su Ética protestante y el espíritu del capitalismo (trad. Luis Legaz Lacambra). Orbis, Barcelona 1985.

${ }^{60}$ Therborn, Göran: op. cit. pág. 55.

${ }^{61}$ Bourdieu, Pierre: op. cit. pág. 137, la cursiva es mía. 